\title{
Tribological Behavior of Novel CNTs-Based Lubricant Grease in Steady-State and Fretting Sliding Conditions
}

\author{
Adolfo Senatore ${ }^{1, *(\mathbb{D}}$, Haiping Hong ${ }^{2}$, Veronica $\mathrm{D}^{\prime} \mathrm{Urso}^{1}$ and Hammad Younes ${ }^{2}$ \\ 1 Department of Industrial Engineering, University of Salerno, via Giovanni Paolo II, 132, \\ I-84084 Fisciano, Italy; v.durso3@studenti.unisa.it \\ 2 Department of Electrical Engineering, South Dakota School of Mines and Technology, \\ Rapid City, SD 57701, USA; Haiping.Hong@sdsmt.edu (H.H.); Hammad.Younes@sdsmt.edu (H.Y.) \\ * Correspondence: a.senatore@unisa.it
}

check for

updates

Citation: Senatore, A.; Hong, H.; D'Urso, V.; Younes, H. Tribological Behavior of Novel CNTs-Based Lubricant Grease in Steady-State and Fretting Sliding Conditions. Lubricants 2021, 9, 107. https://doi.org/ 10.3390/lubricants9110107

Received: 15 September 2021 Accepted: 26 October 2021 Published: 29 October 2021

Publisher's Note: MDPI stays neutral with regard to jurisdictional claims in published maps and institutional affiliations.

Copyright: (C) 2021 by the authors. Licensee MDPI, Basel, Switzerland. This article is an open access article distributed under the terms and conditions of the Creative Commons Attribution (CC BY) license (https:/ / creativecommons.org/licenses/by/ $4.0 /)$.

\begin{abstract}
The tribological behavior of novel $7.5 \mathrm{wt} \%$ carbon nanotube-based lubricant greases in PAO (polyalphaolefin) oil with and without $1.0 \mathrm{wt} \% \mathrm{MoS}_{2}$, together with several other commercial greases such as calcium, lithium, were studied. The test results showed a marked reduction of frictional coefficient achieved by the CNTs based grease samples with an average benefit of around $30 \%$ compared to conventional greases. The steady state test under $1.00 \mathrm{GPa}$ average contact pressure in a mixed lubrication regime and the fretting test showed the best results in terms of friction reduction obtained by CNTs greases. Steady state tests at higher average contact pressure of 1.67 GPa proved to have a lower friction coefficient for $\mathrm{CNTs}$ grease containing $\mathrm{MoS}_{2}$; otherwise $\mathrm{CNTs}$ grease without $\mathrm{MoS}_{2}$ showed an average value of $\mathrm{CoF}$ comparable to calcium and lithium greases, both in a boundary and a mixed regime. The protection against wear, a considerable decrease $(-60 \%)$ of reference parameter was measured with CNTs grease with $\mathrm{MoS}_{2}$ (NLGI 2) in comparison with the worst conventional grease and $-22 \%$ in comparison with the best conventional grease. The data indicated that our novel carbon nanotube greases show superior tribological properties and will have promising applications in the corresponding industry.
\end{abstract}

Keywords: grease; PAO; CNTs; wear; coefficient of friction; tribological behavior; fretting; sliding

\section{Introduction}

Most of the failures and energy losses of mechanical systems are due to friction and wear, so lubrication could be considered one of the most effective ways to reduce surface damage and energy dissipations. Lubricants decrease wear and friction in mutual contacts between coupled surfaces. Several types of additives in lubricants (e.g., Extreme pressure (EP), antiwear (AW), Frequency-modulation (FM)) yield specific requirements for good lubrication. The previous research proved that lubricants' tribological properties have been improved using nanoparticles as a new additive [1]. Nanoadditives enhance the lubricating characteristics due to the tiny particles' size and morphology that can fill the surface asperities and realize the lubrication mechanisms (i.e., rolling effect, mending effect, polishing effect, protective film formation [1,2]). Research has focused on several typologies of nanomaterials, such as chalcogenides, metal oxides, and carbon-based additives in oil or grease [3-9]. For instance, experimental research has proved that metal oxides added to lithium grease can significantly improve the lubricants' tribological behavior. As reported in [10], the lubricating properties of grease specimens with different concentrations of $\mathrm{Al}_{2} \mathrm{O}_{3}$ nanoparticles have been investigated using a pin-on disc apparatus. Results have shown a reduction of COF and wear scar width by approximately $57.9 \%$ and $47.5 \%$, respectively. Moreover, research has been carried out on the effects of agglomeration of selected nanoparticles, such as zirconia, within a lithium grease [11]. Experimental analysis on friction properties has proved the addition of $1 \mathrm{wt} \% \mathrm{ZrO}_{2}$ nanoparticles to pure lithium grease can decrease the friction coefficient to 50\%. Nevertheless, the agglomeration of 
$\mathrm{ZrO}_{2}$ nanoparticles in the lithium grease can increase the friction coefficient by two times compared to that for the pure grease. Applying nanomaterials and nanotechnology in lubrication has also become increasingly popular to achieve green manufacturing and its sustainable development. To this end, water-based nanolubricants are emerging as promising alternatives to the traditional oil-based lubricants [12].

As nanomaterials are of growing interest for lubricating systems, more and more attention has been given to carbon nanotubes (CNTs). Their tubular structure exhibits excellent mechanical characteristics (i.e., high tensile strength, high elastic modulus [13,14], high thermal and electrical conductivity [15-18]) and good lubrication properties, enhancing wear and coefficient Friction (CoF) reduction [19].

In the last few years, the use of carbon nanotubes as additives in lubricating oil/grease has increased, and many research studies have proved that CNTs, with the single-wall (SWCNT) or multi-wall (MWCNT) structure, can improve the tribological performances of the lubricant significantly, compared to a traditional one. For instance, the tribological behavior of Co-based single wall carbon nanotubes has been investigated as an antiwear and extreme pressure additive to SAE base oil. Friction and wear have been evaluated, and it has been found that the SWCNTs are more efficient than the commercial oil additives; tests proved the decreasing of the friction coefficient, using only $0.5 \mathrm{wt} \%$ carbon nanotubes to the base oil [20]. Different concentrations of multi-wall carbon nanotubes have been added as additives to two mineral oils; the samples were tested for their antiwear, load carrying capacity, and friction coefficients. The experimental results have shown that the addition of MWCNTs to base oils exhibited good friction reduction and antiwear properties: wear and friction have decreased by $-68 \% /-39 \%$ and $-57 \% /-49 \%$, respectively, in the case of MWCNTs-based mineral oils compared with the two reference mineral oils [21].

A weighted percentage of $1 \mathrm{wt} \%$ of carbon nanotubes in a traditional lithium-based grease can improve EP properties, load-carrying capacity, AW, and friction performances [22]. Moreover, the CNTs concentration affects the lubricant's tribological characteristics, as shown in [23], whereas the different percentage of nanoparticles has been added to a common calcium-based grease. Carbon nanotubes have been added together with other nanoparticles in a calcium grease, and improvements have been observed not only in reduced wear and friction but also in other important characteristics of a lubricant grease, such as shear stress, apparent viscosity, drop point, and thermal conductivity [24-26].

CNTs have been used with different nanoparticles and materials to improve the tribological behavior of lubricants [27-29]. Wang et al. coated the surface of carbon nanotubes with a uniform copper nanoparticle. This successful coating for the nanocomposite was achieved through the modification of the CNTs surface with spontaneous polydopamine (PDA). The friction and wear were reduced by $33.5 \%$ and $23.7 \%$ when $0.2 \mathrm{wt} \%$ of the prepared nanocomposite was used. The improvement in the lubrication properties was attributed to uniform coating and the formation of transfer films on the rubbing surfaces [30]. Akbarpour et al. studied the wear and friction of a composite made of MWNTs, copper, and $\mathrm{SiC}$. The result revealed that $2 \mathrm{vol} \%$ of $\mathrm{SiC}$ and $4 \mathrm{vol} \% \mathrm{CNT}$ and Copper had the highest wear resistance and a lower friction coefficient [31]. Song et al. used the chemical vapor deposition technique to grow several layers of $\mathrm{MoS}_{2}$ on the surface of the carbon nanotubes. The CNTs were oxidized by acids to prepare strongly oxidized CNTs (SOCNTs). $0.02 \mathrm{wt} \%$ of SOCNTs with dibutyl phthalate (DBP) achieved a reduction in the friction coefficient and wear scar diameter by $57.93 \%$ and $19.08 \%$, respectively [32].

According to the ASTM D288, the definition of lubricating grease is "a solid to a semi-fluid product of a thickening agent in a liquid lubricant. Other ingredients imparting special properties may be included" [33]. The thickener agent gives a solid to semi-fluid structure to the lubricant grease and affects many of its main properties. Recently, a new class of nanogrease has been defined using carbon nanotubes as a thickener phase in the lubricant. SWCNTs and MWCNTs have been added into the polyalphaolefin (PAO) oils to form stable and homogeneous CNT grease with potential heat transfer, conductive, and lubricative properties. The rheological investigation of these CNT greases has 
provided information concerning the formation of a stable tridimensional structure and particle-particle interactions of CNT suspensions, explaining its excellent lubricating performances [34]. The characterizations of four selected CNT greases have shown high dropping temperatures, very low oil leaking percentages even at high temperatures, and a substantial increase in thermal and electrical conductivities [35]. Experimental tests have been carried out to investigate the enhancing tribological properties of CNT grease compared to the base oil grease. It has been showing that CNTs play a more significant part in lubrication, which greatly improves the lubricating effect on wear and friction [36-39].

In this research, CNTs, single-wall and multi-wall (SWCNTs and MWCNTs) have been added separately into polyalphaolefin oils (DURASYN_166), with and without $M_{2} S_{2}$, to form stable and homogeneous CNT greases. The tribological behavior has been investigated in steady-state and fretting sliding conditions, and performance comparisons have been conducted with commercial calcium and lithium greases.

\section{Experimental Section}

\subsection{Materials}

SWCNTs and MWCNTs were purchased from Carbon Nanotechnologies Incorporation (CNI, Houston, TX, USA now Unidym Inc). Carbon nanotubes were used as received with no further purification or functionalization. SWCNTs are of average diameter $1.4 \mathrm{~nm}$ and are found in "ropes" which are typically *20 nm in diameter or *50 tubes per rope with lengths of $0.5-40$ microns. Thermal conductivity is around $35 \mathrm{~W} / \mathrm{mK}$ at room temperature. No electrical conductivity data are available. The sample purity is $70-90 \mathrm{vol} \%$. There are $10-25 \mathrm{vol} \%$ carbon black and $<5 \mathrm{vol} \%$ residual catalyst metal impurities in the samples. For MWCNTs, the diameter is around $20-40 \mathrm{~nm}$, and the standard length is around $0.5-40$ microns. No thermal and electrical conductivity data are available. The sample purity is around $90 \mathrm{vol} \%$. There are $<10 \mathrm{vol} \%$ carbon black (amorphous carbon) and a small amount $(<0.5 \mathrm{vol} \%)$ of catalyst metal impurities in the samples. DURASYN 166 is a commercial polyalphaolefin oil product purchased from Chemcentral (Chicago, IL, USA). $\mathrm{MoS}_{2}$ nanoparticles were purchased from Sigma Aldrich (St. Louis, MO, USA). Since traditional calcium and lithium greases are commonly employed in industrial lubrication, they were chosen in order to set a comparison to the tribological performance of CNTs grease. Commercial samples of Eurogrease I.G. NLGI 2 calcium based, Eurogrease C.M.3 NLGI 3 lithium based and Eurogrease G.O. NLGI 2 lithium based with MoS2 additives from Rilub SpA (Ottaviano, Italy) were used as reference.

\subsection{Grease Fabrication}

Sonication was performed using a Branson Digital Sonifier, model 450. A three-roll mill by Ross Engineering Inc. (Savannah, GA, USA) was used to incorporate the CNTs to make the stable and well-dispersed greases. The carbon nanotube greases were made by adding a calculated amount of nanotubes (single-wall or multi-wall) into a beaker that contained an appropriate amount of oil (e.g., DURASYN 166, Polyalphaolefin). $5 \mathrm{wt} \%$ $\mathrm{MoS}_{2}$ was added to carbon nanotube grease to see how the additive would influence the physical property. In this paper, we use two greases: singe-wall carbon nanotube (SWCNTs) grease and multi-wall carbon nanotube (MWCNTs) grease with $\mathrm{MoS}_{2}$. The experimental procedure to make nano grease is as follows: first, the fluids were sonicated 5-10 times, each time 1-2 min. Second, the fluids were poured into a three-roll mill, repeated 5-8 times. Finally, black, stable, and well-dispersed greases were manufactured and collected.

\subsection{Tribological Characterization}

The tribological test rig for exploring nano additives' effectiveness is the Wazau TRM 100 (Dr.-Ing. Georg Wazau Meß Prüfsysteme GmbH, Berlin, Germany) with the ball-onrotational disc setup as in the drawing in Figure 1. The selected mating materials are: (ball) steel $\mathrm{X} 45 \mathrm{Cr} 13$, hardness: HRC 52-54, diameter: $8 \mathrm{~mm}$, mean surface roughness: 
$0.2 \mu \mathrm{m}$; (disc) steel X155CrVMo12-1, hardness: HRC 60, diameter: $105 \mathrm{~mm}$, mean surface roughness: $0.5 \mu \mathrm{m}$.

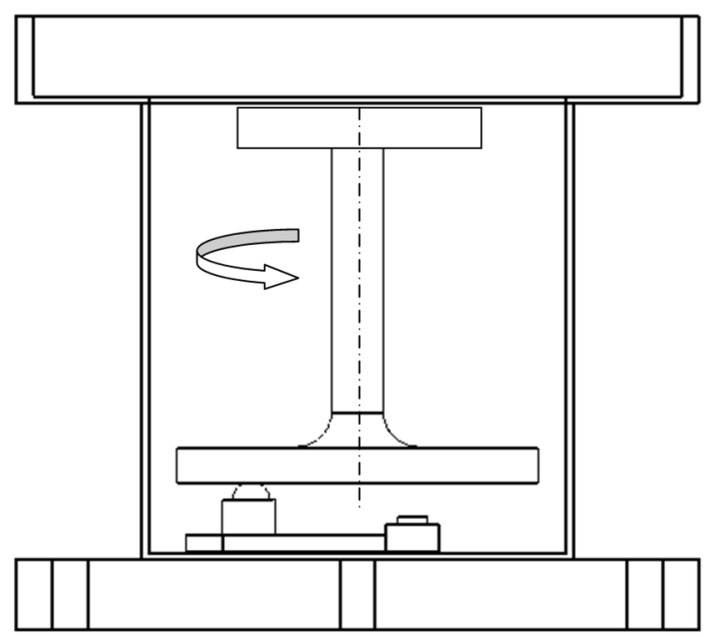

Figure 1. Ball on disk setup and rotational tribometer.

The tribological tests were carried out to investigate two different lubrication regimes and fretting operating conditions. A normal load level of 20 or $95 \mathrm{~N}$ was applied to attain an average hertzian contact pressure around 1.00 and $1.67 \mathrm{GPa}$, respectively. The average grease temperature was kept constant at room temperature in each test. The relative motion between the steel ball and the disc was pure sliding at two-speed levels: 5 and $500 \mathrm{~mm} / \mathrm{s}$. According to previous results for the same tribopair geometry, average contact pressure, temperature, the boundary lubrication regimes, and the mixed lubrication superposition of the boundary, and elastohydrodynamic lubrication (EHL) regimes were covered. The fretting test was designed by applying an alternate rotating motion to the disk to cover a $75^{\circ}$ angle with $2 \mathrm{~Hz}$ as the frequency.

Both the ball and the disk were pre-cleaned, and the grease was then evenly pasted on the disk sliding pathway by forming a layer with $2 \mathrm{~mm}$ thickness. The test length was $60 \mathrm{~min}$ in steady-state condition and $120 \mathrm{~min}$ for fretting. Thus, the actual sliding distance was 18 and $1800 \mathrm{~m}$ for the speed of 5 and $500 \mathrm{~mm} / \mathrm{s}$, respectively. The sliding distance was $1131 \mathrm{~m}$ for the fretting portion/phase of testing.

The friction coefficient has been indirectly measured in real-time using a torque sensor located under the ball holder plate. After each tribotest, the wear damage circle on the top of the worn steel ball was offline measured through a 3D confocal microscopy.

\section{Results and Discussion}

\subsection{Tribological Results}

The results of the frictional tests were performed under the operating conditions described above in Section 2.3. In both, the investigated lubrication regimes are summarized in Table 1. Tests were also performed to analyze the behavior of the lubricating grease samples for the wear damage of the steel ball surface. In particular, the worn surface of the steel ball was analyzed using a 3D confocal microscope to measure the wear scar diameter (WSD). According to the ISO/IEC Guide 98-3:2008, the expanded uncertainty of the frictional data and WSD measurements are $5.0 \times 10^{-3}$ and $1 \mu \mathrm{m}$, respectively, by assuming the coverage factor $\mathrm{k}=2$.

The high frequency acquired frictional data were processed through a rolling mean to filter out spike values and typical oscillations of such measurements.

The steady-state test at $5 \mathrm{~mm} / \mathrm{s}$ of sliding speed and initial average hertzian pressure equal to $1.00 \mathrm{GPa}$ provided the graphs collected in Figure 2. The graphs show CoF values in a narrow range of $0.12-0.14$, with high similarities between Calcium soap, Lithium soap, and CNT-based grease ( 0.13 as average). The two remaining samples, i.e., Lithium 
soap with $\mathrm{MoS}_{2}$ and CNTs with $\mathrm{MoS}_{2}$ provided lightly higher CoF. This outcome confirms the effectiveness of $\mathrm{MoS}_{2}$ as an additive in oil and lubricant grease in extreme-pressure conditions, tougher than non-critical conditions as from this test.

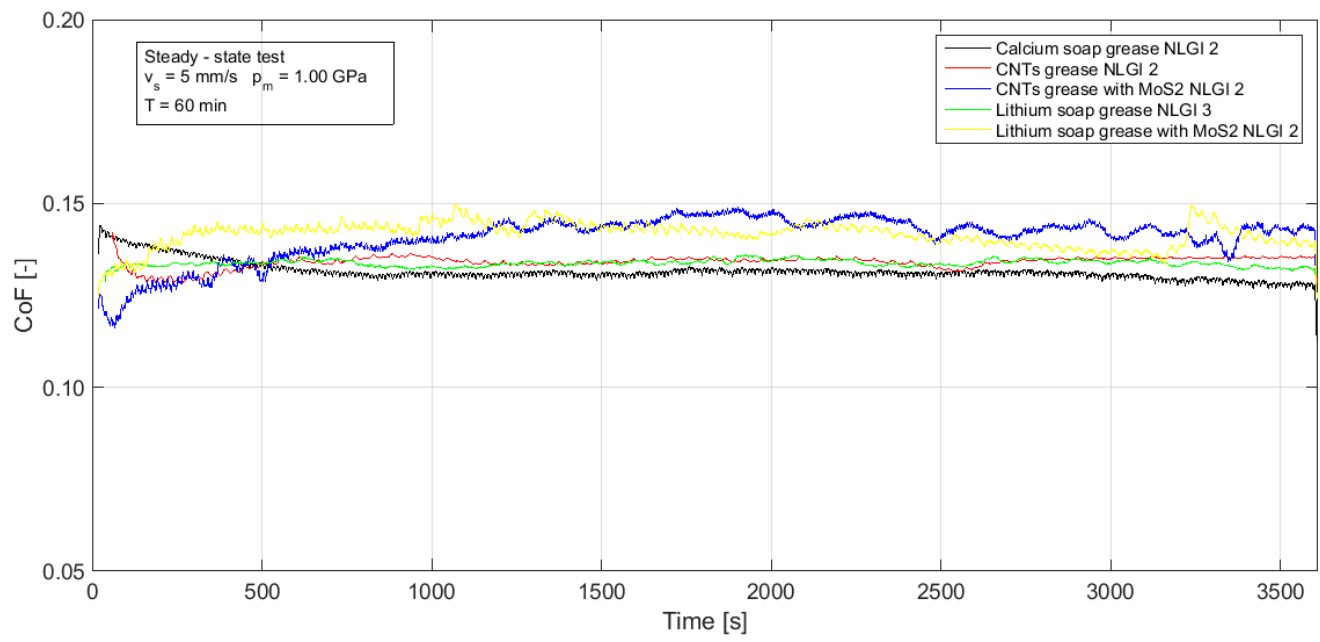

Figure 2. Friction coefficient in boundary regime under $1.00 \mathrm{GPa}$ average contact pressure.

In Figure 3, the increasing value of sliding speed $(500 \mathrm{~mm} / \mathrm{s})$ results in a marked difference in the steady-state value of the friction coefficient. Except for the Calcium soap grease, showing high CoF variability in the first 25 min of the test, all the samples reach their asymptotic value quickly. The former result is not unexpected as the Calcium soap grease with NLGI grade 2 does not bear sliding condition with speed as high as $500 \mathrm{~mm} / \mathrm{s}$; the latter behavior underlines a good reduction achieved by the CNTs based samples with CoF in the range $0.11-0.12$ with a reduction up to $-35 \%$ compared to conventional greases over the second part of the test characterized by stationary behavior.



Figure 3. Friction coefficient in mixed regime under 1.00 GPa average contact pressure.

The measurements at a sliding speed of $5 \mathrm{~mm} / \mathrm{s}$ and initial average hertzian pressure of $1.67 \mathrm{GPa}$ are shown in Figure 4. In these conditions, the friction coefficient values are in the range $0.10-0.13$, and for this test, the trend of the graphs is relatively constant. Again, the CoF values are comparable for some samples, such as Lithium soap, Lithium soap with $\mathrm{MoS}_{2}$ additive, and CNTs based grease. Interesting performances are observable for the Calcium soap grease and CNTs based grease with $\mathrm{MoS}_{2}$ additive, whose CoFs are around 0.10. This behavior is expected for these tested samples. As previously explained, the 
Calcium based grease allows good tribological behavior in non-critical working conditions, e.g., at low temperatures and low speeds, whereas the properties of molybdenum bisulphide and carbon nanotubes, combined in the grease sample increase its tribological characteristics.

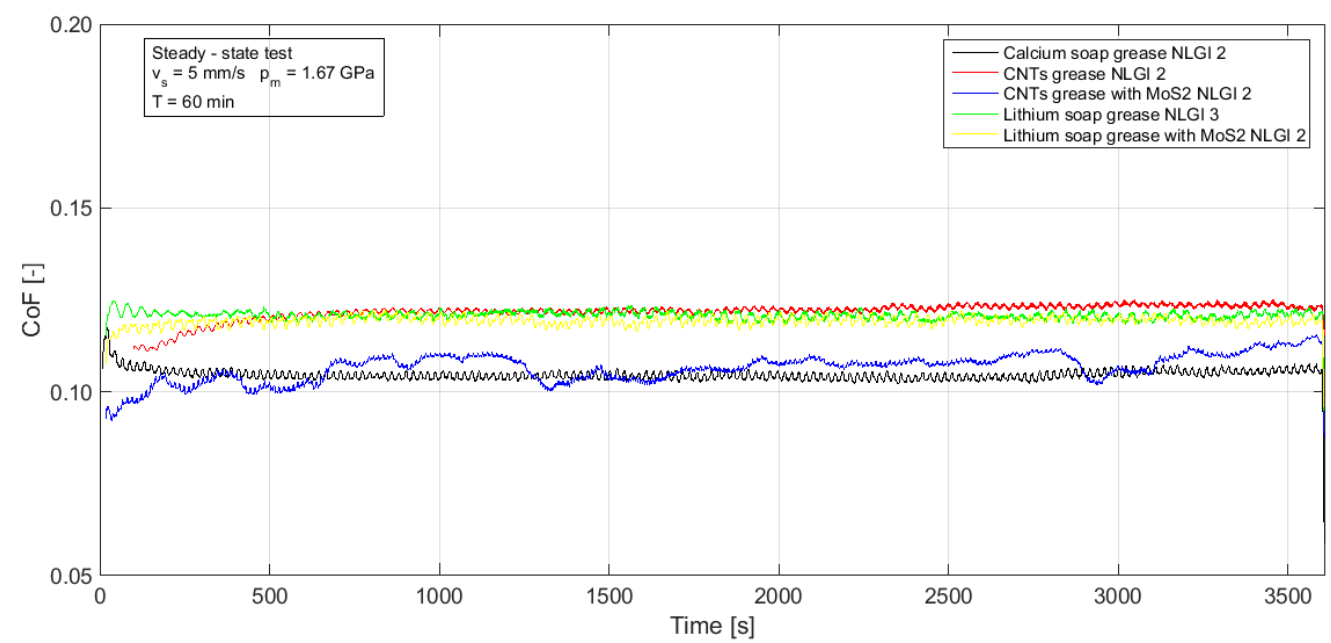

Figure 4. Friction coefficient in boundary regime under $1.67 \mathrm{GPa}$ average contact pressure.

Furthermore, all samples exhibited decreased friction coefficient values while increasing normal load, demonstrating good lubricating capacity under high loads and low speeds in a boundary lubrication regime. As a matter of fact, the friction coefficient showed a tendency to decrease with increasing contact pressure. According to previous works [3,4], the shear stress increased less rapidly in proportion to the contact pressure. This leads to a reduction of the friction coefficient with increasing pressure at a given level of sliding speed.

Among the frictional tests discussed in this paper in a steady-state condition, the most demanding combination of sliding speed and load is given by the test in a mixed lubrication regime obtained at $500 \mathrm{~mm} / \mathrm{s}$ and $1.67 \mathrm{GPa}$, seen in Figure 5. Once again, it is worth noting that the trend of the graphs in Figure 5 is nearly constant for all samples, except for Calcium soap grease with CoF peaks as high as 0.27 , as is further confirmed in the discussion regarding the test at low speed and load, Figure 4.

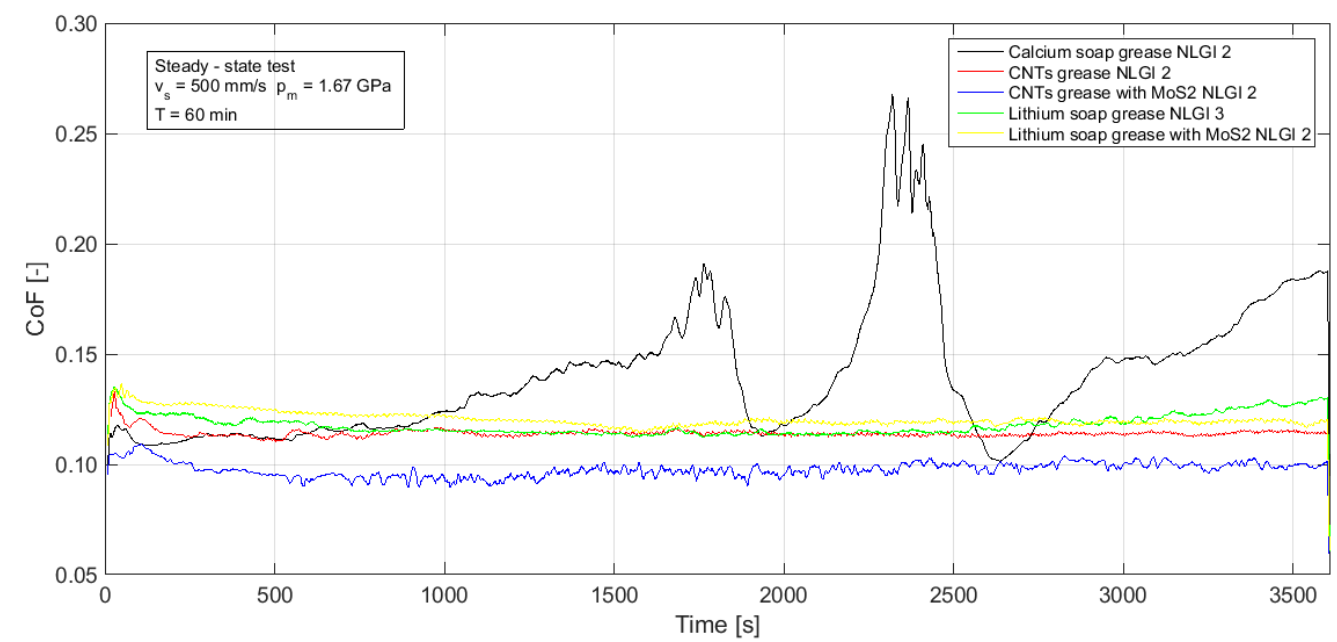

Figure 5. Friction coefficient in mixed regime under 1.67 GPa average contact pressure. 
The samples of Lithium soap, Lithium soap with $\mathrm{MoS}_{2}$, and CNTs based on the CoF curves are approximately superimposable, presenting CoF falling in the same range of the boundary test at $1.67 \mathrm{GPa}, 0.12-0.13$. In contrast, the CNTs based grease with $\mathrm{MoS}_{2}$ showed a noticeable reduction in $\mathrm{CoF}:-28 \%$ compared to the three previous samples, by attaining an outstanding reduction to 0.09 .

The last set of graphs collected in Figure 6 includes measurements of frictional behavior exhibited by the five grease samples under the characteristic fretting condition by applying sliding alternate motion to the frictional conjunction with frequency $2 \mathrm{~Hz}$. The test length was 120 min with a covered sliding distance of $1131 \mathrm{~m}$. In fretting conditions, unlike the previous ones in which the sliding speed is constant, stability at high speed is not expected for each $\mathrm{CoF}$ graph since the oscillating conditions may require a longer running-in time for the tribopairs' steel surfaces as well as the grease thickener structure. Along with the already exhibited lack of stationarity of the Calcium soap grease, even the Lithium soap and Lithium soap with $\mathrm{MoS}_{2}$ additive show high variability of CoF over the whole 2 -h test with average values attaining $0.15,0.13$, respectively.

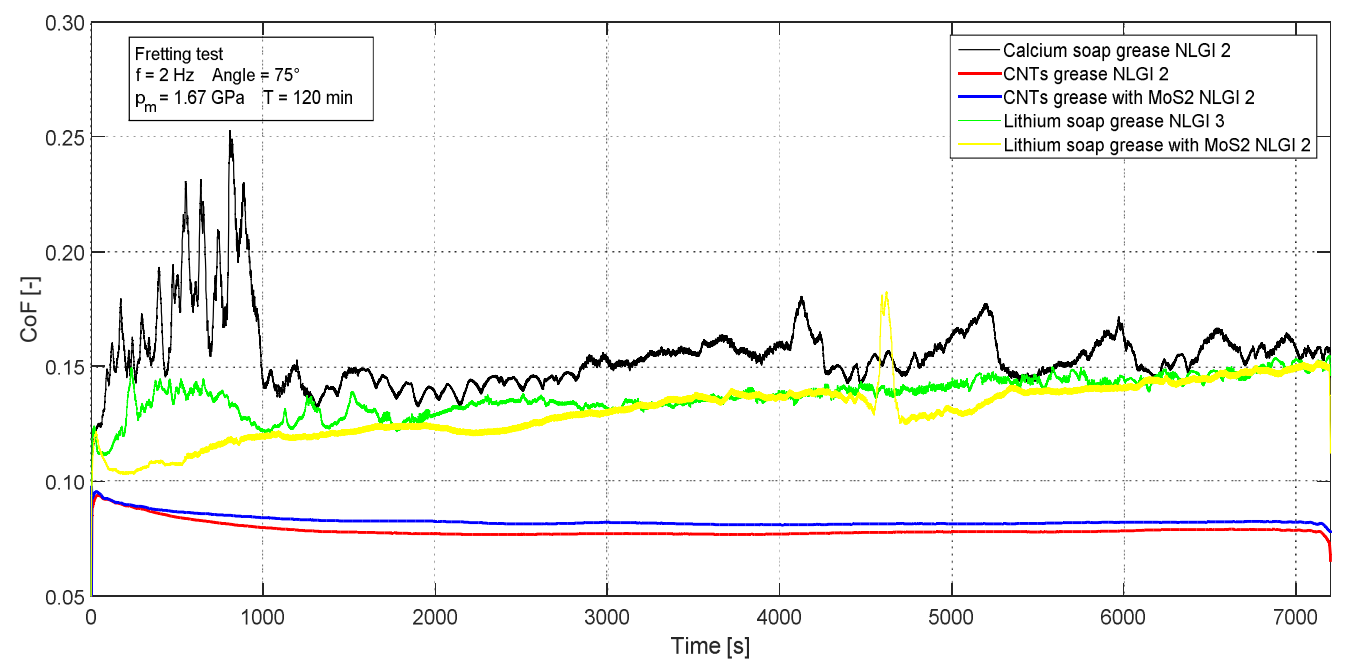

Figure 6. Friction coefficient in the fretting test under 1.67 GPa average contact pressure.

The CNTs based greases show lower CoF values, with an average value under 0.09 and a remarkable reduction of $-35 \%$ with respect to the best performing conventional grease. Even the amplitude of CoF oscillations in testing CNTs based grease is drastically reduced by showing enhanced structural stability of the thickener and overall industrial reliability of the lubricant.

The frictional and wear data also correlate well, resulting in a positive correlation (0.8 Pearson index), Tables 1 and 2. This outcome is not obvious in such test conditions. Table 3 underlines the outstanding results achieved by using CNTs based grease with wear parameter reduction close to $-60 \%$ in comparison with the worst conventional grease and $-22 \%$ in comparison with the best conventional grease. 
Table 1. The average friction coefficient in boundary and mixed regime.

\begin{tabular}{ccccc}
\hline Scheme & \multicolumn{2}{c}{$\begin{array}{c}\text { Friction } \\
\text { Coefficient in } \\
\text { Boundary Regime [-] }\end{array}$} & \multicolumn{2}{c}{$\begin{array}{c}\text { Friction } \\
\text { Coefficient in } \\
\text { Mixed Regime [-] }\end{array}$} \\
\cline { 2 - 5 } & $\begin{array}{c}\text { Contact } \\
\text { Pressure }\end{array}$ & $\begin{array}{c}\text { Contact } \\
\text { Pressure }\end{array}$ & $\begin{array}{c}\text { Contact } \\
\text { Pressure }\end{array}$ & $\begin{array}{c}\text { Contact } \\
\text { Pressure }\end{array}$ \\
& $\mathbf{1 . 0 0 ~ G P a}$ & $\mathbf{1 . 6 7 ~ G P a}$ & $\mathbf{1 . 0 0 ~ G P a}$ & $\mathbf{1 . 6 7 ~ G P a}$ \\
\hline Ca soap grease NLGI 2 & 0.13 & 0.11 & 0.15 & 0.16 \\
Li soap grease NLGI 3 & 0.13 & 0.13 & 0.14 & 0.12 \\
Li soap grease with MoS 2 NLGI 2 & 0.14 & 0.12 & 0.15 & 0.13 \\
CNTs grease NLGI 2 & 0.13 & 0.12 & 0.12 & 0.12 \\
CNTs grease with MoS NLGI 2 & 0.14 & 0.13 & 0.11 & 0.11 \\
\hline
\end{tabular}

Table 2. Wear scar diameter (WSD) in boundary and mixed regime.

\begin{tabular}{ccccc}
\hline & \multicolumn{2}{c}{$\begin{array}{c}\text { Wear Scar Diameter } \\
\text { (WSD) }\end{array}$} & \multicolumn{2}{c}{$\begin{array}{c}\text { Wear Scar Diameter } \\
\text { (WSD) }\end{array}$} \\
Sample & in Boundary Regime $[\mu \mathrm{m}]$ & in Mixed Regime $[\boldsymbol{\mu m}]$ \\
\cline { 2 - 5 } & $\begin{array}{c}\text { Contact } \\
\text { Pressure }\end{array}$ & $\begin{array}{c}\text { Contact } \\
\text { Pressure }\end{array}$ & $\begin{array}{c}\text { Contact } \\
\text { Pressure }\end{array}$ & $\begin{array}{c}\text { Contact } \\
\text { Pressure }\end{array}$ \\
& $\mathbf{1 . 0 0 ~ G P a}$ & $\mathbf{1 . 6 7 ~ G P a ~}$ & $\mathbf{1 . 0 0 ~ G P a}$ & $\mathbf{1 . 6 7 ~ G P a}$ \\
\hline Ca soap grease NLGI 2 & 228 & 385 & 407 & 808 \\
Li soap grease NLGI 3 & 630 & 268 & 358 & 557 \\
Li soap grease with MoS 2 NLGI 2 & 321 & 307 & 398 & 551 \\
CNTs grease NLGI 2 & 195 & 333 & 260 & 930 \\
CNTs grease with MoS NLGI 2 & 231 & 333 & 300 & 556 \\
\hline
\end{tabular}

Table 3. The friction coefficient and wear scar diameter in the fretting test.

\begin{tabular}{ccc}
\hline Sample & $\begin{array}{c}\text { Friction } \\
\text { Coefficient in } \\
\text { Fretting Test [-] }\end{array}$ & $\begin{array}{c}\text { Wear Scar Diameter } \\
\text { (WSD) } \\
\text { in Fretting Test [ } \mu \mathrm{m}]\end{array}$ \\
\hline Ca soap grease NLGI 2 & 0.16 & 915 \\
Li soap grease NLGI 3 & 0.15 & 547 \\
Li soap grease with MoS 2 NLGI 2 & 0.13 & 481 \\
CNTs grease NLGI 2 & 0.08 & 407 \\
CNTs grease with MoS MLGI 2 $^{2}$ NLG & 0.09 & 374 \\
\hline
\end{tabular}

\subsection{Surface Analysis Results}

The SEM images were acquired on the worn surfaces of steel ball specimens after the fretting test. By comparing SEM-XRD spectra collected on the worn surface of the steel ball specimen after tribological tests with conventional greases and CNTs based grease, a significant difference in carbon content was found on the steel surface. As shown in Figure 7, the carbon content on the steel ball's worn surface after test with Calcium soap grease is around $15 \%$, and other SEM measurements confirm this on a different portion of the worn surface. 


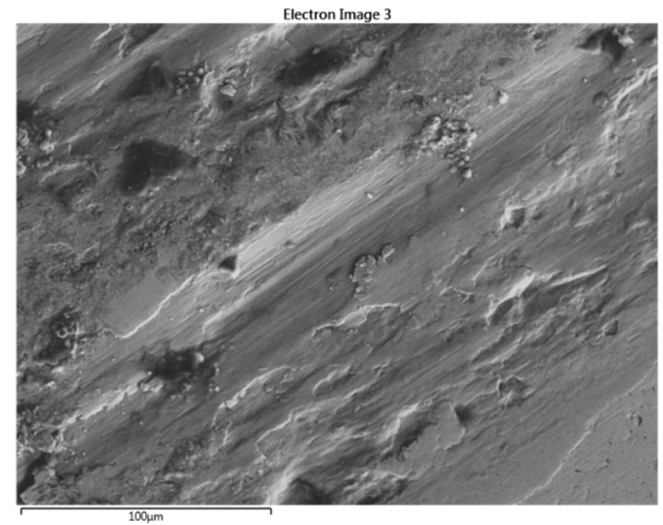

(a)

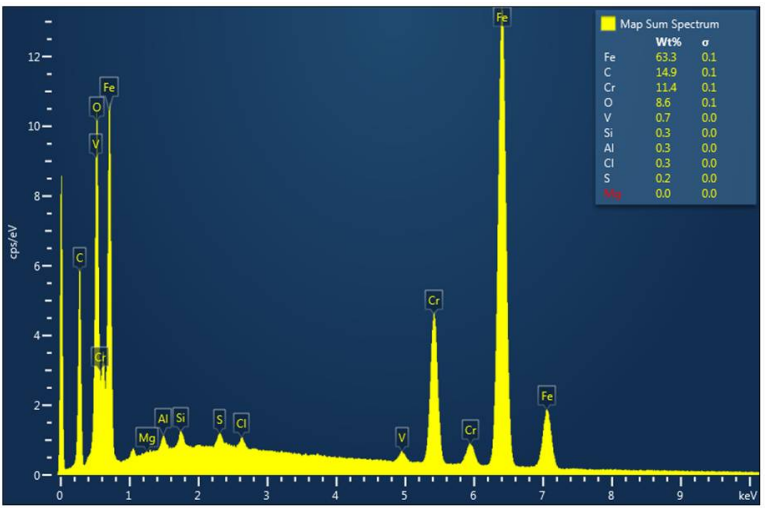

(b)

Figure 7. (a) SEM image of a worn surface ball of steel ball: Calcium soap grease; (b) EDX spectrum: Calcium soap grease.

The same analysis performed on the steel ball's worn surface post-tribological test with CNTs based grease shows lower carbon content (around 6-8\%), Figure 8. In the same spectrum, it is worth noting the presence of Molybdenum.

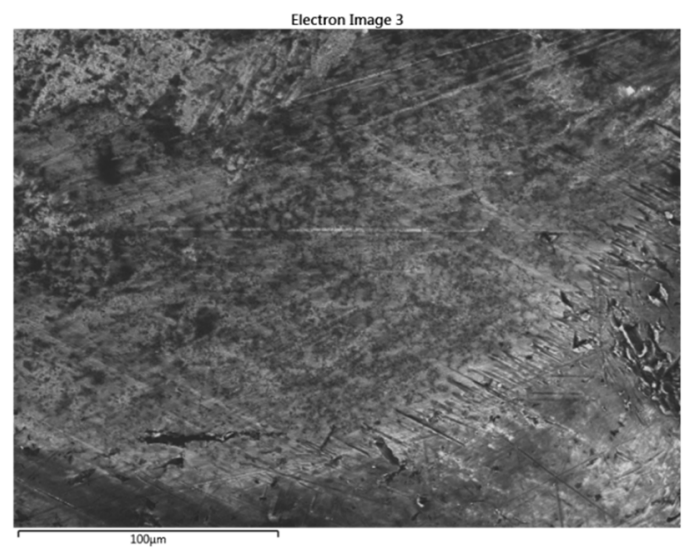

(a)

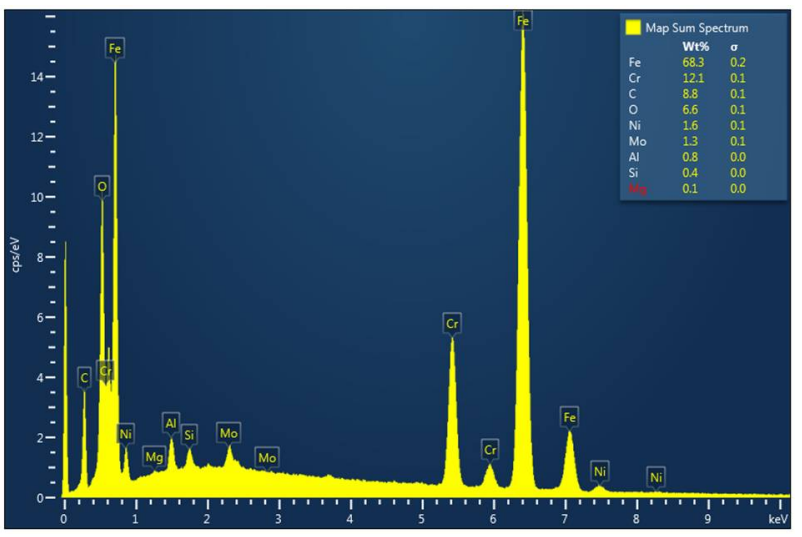

(b)

Figure 8. (a) SEM image of a worn surface ball of steel ball: CNTs based grease with $\mathrm{MoS}_{2}$; (b) EDX spectrum: CNTs based grease with $\mathrm{MoS}_{2}$.

The well-known literature analysis of the friction reduction mechanism introduced by nanoparticles as lubricant additives finds in the following list the more convincing physical explanations: rolling-sliding "rigid" motions together with flexibility properties, nano additive exfoliation, and material transfer to the metal surface to form the so called "tribofilm" or "tribolayer", electronic effects in tribological interfaces, surface roughness improvement effect or "mending"; along with the more classical hypothesis of surface sliding on lower shear stress layers due to weak interatomic forces, valid also for microscale additives used for decades. In the case of the samples proposed in this paper, along with the transfer of nanoparticles from semifluid lubricant to steel mating surfaces, CNTs used as sole thickener seem to provide to the bulk structure of the grease a marked stability of the tribological response over the whole spectrum of the performed tests from a qualitative point of view. From a quantitative point of view, frictional reduction is always good, the CoF has a marked reduction in fretting conditions. On the other hand, wear reduction is substantial only in the case of the fretting test and further optimization may be needed to increase wear protection in a broader range of load/speed combinations. The outstanding behavior in fretting conditions could be attributed to a more consistent and 
fatigue-resistant performance of CNTs thickener in comparison to conventional greases based on metallic soap.

\section{Conclusions}

The tribological behavior of novel carbon nanotube-based lubricant greases in PAO with and without $\mathrm{MoS}_{2}$ was studied. The test results showed a marked reduction of frictional coefficient achieved by the CNTs based grease samples with an average benefit of around $-30 \%$ compared to conventional greases. The steady state test under $1.00 \mathrm{GPa}$ average contact pressure in a mixed lubrication regime and the fretting test showed the best results in terms of friction reduction obtained by CNTs greases. Steady state tests at a higher average contact pressure of $1.67 \mathrm{GPa}$ proved to have a lower friction coefficient for CNTs grease containing $\mathrm{MoS}_{2}$; otherwise, CNTs grease without $\mathrm{MoS}_{2}$ showed an average value of coefficient of friction comparable to commercial calcium and lithium greases, both in a boundary and a mixed regime. Related to the protection against wear, a considerable decrease $(-60 \%)$ of reference parameter WSD has been measured in the fretting tests with CNTs grease with $\mathrm{MoS}_{2}$ (NLGI 2) in comparison with the worst conventional grease and $-22 \%$ in comparison with the best conventional grease. The wear protection increase offered by novel greases was not relevant in the steady state test and further investigations aimed at optimizing such a behavior should be developed. The overall results indicated that the novel carbon nanotube greases show superior tribological properties and will have promising applications in the corresponding industry.

Author Contributions: Conceptualization, A.S. and H.H.; methodology, A.S. and H.H.; software, V.D.; validation, V.D.; investigation, A.S., V.D., H.H. and H.Y; data curation, V.D.; writing-original draft preparation, V.D.; writing-review and editing, A.S., H.H. and H.Y.; supervision, H.H.; funding acquisition, H.H. and A.S. All authors have read and agreed to the published version of the manuscript.

Funding: The authors would like to acknowledge the financial support provided through Army Research Lab (Cooperative agreement W911NF 15-2-0034-S), the South Dakota Advanced Manufacturing Process Technology Transition and Training Center (AMPTECH), University of Salerno "FARB projects".

Conflicts of Interest: The authors declare no conflict of interest.

\section{References}

1. Anurag, S.; Prashant, C.; Mamatha, T.G. A review on tribological performance of lubricants with nanoparticles additives. Mater. Today Proc. 2020, 25, 586-591. [CrossRef]

2. Gulzar, M.; Masjuki, H.H.; Kalam, M.A.; Varman, M.; Zulkifli, N.W.M.; Mufti, R.A.; Zahid, R. Tribological performance of nanoparticles as lubricating oil additives. J. Nanopart. Res. 2016, 18, 223. [CrossRef]

3. Yadgarov, L.; Petrone, V.; Rosentveig, R.; Feldman, Y.; Tenne, R.; Senatore, A. Tribological studies of rhenium doped fullereneLike $\mathrm{MoS}_{2}$ nanoparticles in boundary, mixed and elastohydrodynamic lubrication conditions. Wear 2013, 297, 1103-1110. [CrossRef]

4. Altavilla, C.; Sarno, M.; Ciambelli, P.; Senatore, A.; Petrone, V. New "chimie douce" approach to the synthesis of hybrid nanosheets of $\mathrm{MoS}_{2}$ on CNT and their anti-friction and anti-wear properties. Nanotechnology 2013, 24, 125601. [CrossRef]

5. Wu, H.; Zhao, J.; Cheng, X.; Xia, W.; He, A.; Yun, J.-H.; Huang, S.; Wang, L.; Huang, H.; Jiao, S.; et al. Friction and wear characteristics of TiO2 nano-additive water-based lubricant on ferritic stainless steel. Tribol. Int. 2018, 117, 24-38. [CrossRef]

6. Guzman Borda, F.L.; Ribeiro de Oliveira, S.J.; Seabra Monteiro Lazaro, L.M.; Kalab Leiróz, A.J. Experimental investigation of the tribological behavior of lubricants with additive containing copper nanoparticles. Tribol. Int. 2018, 117, 52-58. [CrossRef]

7. Pape, F.; Pope, G. Investigations on Graphene Platelets as Dry Lubricant and as Grease Additive for Sliding Contacts and Rolling Bearing Application. Lubricants 2020, 8, 3. [CrossRef]

8. Mello, V.S.; Trajano, M.F.; Guedes, A.E.D.S.; Alves, S.M. Comparison Between the Action of Nano-Oxides and Conventional EP Additives in Boundary Lubrication. Lubricants 2020, 8, 54. [CrossRef]

9. Xu, J.; Cai, R.; Zhang, Y.; Mu, X. Molybdenum disulfide-based materials with enzyme-like characteristics for biological applications. Colloids Surf. B Biointerfaces 2021, 200, 111575. [CrossRef]

10. Nabhan, A.; Rashed, A.; Ghazaly, N.M.; Abdo, J.; Haneef, M.D. Tribological Properties of $\mathrm{Al}_{2} \mathrm{O}_{3}$ Nanoparticles as Lithium Grease Additives. Lubricants 2021, 9, 9. [CrossRef] 
11. Rylski, A.; Siczek, K. The Effect of Addition of Nanoparticles, Especially $\mathrm{ZrO}_{2}$-Based, on Tribological Behavior of Lubricants. Lubricants 2020, 8, 23. [CrossRef]

12. Morshed, A.; Wu, H.; Jiang, Z. A Comprehensive Review of Water-Based Nanolubricants. Lubricants 2021, 9, 89. [CrossRef]

13. Coleman, J.N.; Khan, U.; Blau, W.J.; Gun'ko, Y.K. Small but strong: A review of the mechanical properties of carbon nanotubepolymer composites. Carbon 2006, 44, 1624-1652. [CrossRef]

14. Moghdam, A.D.; Omrani, E.; Menezes, P.L.; Rohatgi, P.K. Mechanical and tribological properties of self-lubricating metal matrix nanocomposites reinforced by carbon nanotubes (CNTs) and graphene-A review. Compos. Part B 2015, 77, 402-420. [CrossRef]

15. Hong, H.; Thomas, D.; Waynick, A.; Yu, W.; Smith, P.; Roy, W. Carbon nanotube grease with enhanced thermal and electrical conductivities. J. Nanopart. Res. 2010, 12, 529-535. [CrossRef]

16. Chen, H.; Wei, H.; Chen, M.; Meng, F.; Li, H.; Li, Q. Enhancing the effectiveness of silicone thermal grease by the addition of functionalized carbon nanotubes. Appl. Surf. Sci. 2013, 283, 525-531. [CrossRef]

17. Yujun, G.; Zhongliang, L.; Guangmeng, Z.; Yanxia, L. Effects of multi-walled carbon nanotubes addition on thermal properties of thermal grease. Int. J. Heat Mass Transf. 2014, 74, 358-367. [CrossRef]

18. Christensen, G.; Yang, J.; Lou, D.; Hong, G.; Hong, H.; Tolle, C.; Widener, C.; Bailey, C.; Hrabe, R.; Younes, H. Carbon nanotube grease with high electrical conductivity. Synth. Met. 2020, 268, 116496. [CrossRef]

19. Martin, J.M.; Ohmae, N. Carbon-Based Nanolubricants. In Nanolubricants; John Wiley \& Sons Ltd.: Chichester, UK, 2008.

20. Curasu, D.L.; Andronescu, C.; Pirva, C.; Ripeanu, R. The efficiency of Co based SWCNT as an AW/EP additive for mineral base oil. Wear 2012, 290-291, 133-139.

21. Khalil, W.; Mohamed, A.; Bayoumib, M.; Osman, T.A. Tribological properties of dispersed carbon nanotubes in lubricant. Fuller. Nanotub. Carbon Nanostruct. 2016, 24, 479-485. [CrossRef]

22. Mohamed, A.; Osman, T.A.; Khattab, A.; Zaki, M. Tribological Behaviour of Carbon Nanotubes as Additive on Lithium Grease. J. Tribol. 2015, 137, 011801. [CrossRef]

23. Kamel, B.M.; Mohamed, A.; Sherbiny, M.E.; Abed, K.A. Tribological behaviour of calcium grease containing carbon nanotubes additives. Ind. Lubr. Tribol. 2016, 68, 723-728. [CrossRef]

24. Mobasher, A.; Khalil, A.; Khashaba, M.; Osman, T. Effect of MWCNTs/Talc powder nanoparticles on the tribological and thermal conductivity performance of calcium grease. Ind. Lubr. Tribol. 2020, 72, 9-14. [CrossRef]

25. Mohamed, A.; Ali, S.; Osman, T.A.; Kamel, B.M. Development and manufacturing an automated lubrication machine test for nano grease. J. Mater. Res. Technol. 2020, 9, 2054-2062. [CrossRef]

26. Mohamed, A.; Tirth, V.; Kamel, B.M. Tribological characterization and rheology of hybrid calcium grease with graphene nanosheets and multi-walled carbon nanotubes as additives. J. Mater. Res. Technol. 2020, 9, 6178-6185. [CrossRef]

27. Pei, X.; Hu, L.; Liu, W.; Hao, J. Synthesis of water-soluble carbon nanotubes via surface initiated redox polymerization and their tribological properties as water-based lubricant additive. Eur. Polym. J. 2008, 44, 2458-2464. [CrossRef]

28. Jia, X.; Huang, J.; Li, Y.; Yang, J.; Song, H. Monodisperse Cu nanoparticles@ $\mathrm{MoS}_{2}$ nanosheets as a lubricant additive for improved tribological properties. Appl. Surf. Sci. 2019, 494, 430-439. [CrossRef]

29. Min, C.; He, Z.; Song, H.; Liu, D.; Jia, W.; Qian, J.; Jin, Y.; Guo, L. Fabrication of novel CeO2/GO/CNTs ternary nanocomposites with enhanced tribological performance. Appl. Sci. 2019, 9, 170. [CrossRef]

30. Wang, Z.; Ren, R.; Song, H.; Jia, X. Improved tribological properties of the synthesized copper/carbon nanotube nanocomposites for rapeseed oil-based additives. Appl. Surf. Sci. 2018, 428, 630-639. [CrossRef]

31. Akbarpour, M.R.; Alipour, S.; Safarzadeh, A.; Kim, H.S. Wear and friction behavior of self-lubricating hybrid Cu-(SiC $+x$ CNT) composites. Compos. B Eng. 2019, 158, 92-101. [CrossRef]

32. Song, W.; Yan, J.; Ji, H. Tribological Study of the SOCNTs@MoS 2 Composite as a Lubricant Additive: Synergistic Effect. Ind. Eng. Chem. Res. 2018, 57, 6878-6887. [CrossRef]

33. ASTM. Standard D288-61. Standard Definitions of Terms Relating to Petroleum; ASTM International: West Conshohocken, PA, USA, 1964.

34. Hong, H.; Younes, H.; Christensen, G.; Horton, M.; Qiang, Y. A Rheological Investigation of Carbon Nanotube Grease. J. Nanosci. Nanotechnol. 2019, 19, 4046-4051. [CrossRef] [PubMed]

35. Hong, H.; Younes, H.; Christensen, G.; Widener, C. Carbon nanotube grease and sustainable manufacturing. Procedia Manuf. 2018, 21, 623-629. [CrossRef]

36. Liu, H.; Ji, H.; Hong, H.; Younes, H. Tribological properties of carbon nanotube grease. Ind. Lubr. Tribol. 2014, 66, 579-583. [CrossRef]

37. Younes, H.; Christensen, G.; Groven, L.; Hong, H.; Smith, P. Three dimensional (3D) percolation network structure: Key to form stable carbon nano grease. J. Appl. Res. Technol. 2016, 14, 375-382. [CrossRef]

38. Christensen, G.; Younes, H.; Hong, G.; Lou, D.; Hong, H.; Widener, C.; Bailey, C.; Hrabe, R. Hydrogen bonding enhanced thermally conductive carbon nano grease. Synth. Met. 2020, 259, 116213. [CrossRef]

39. Younes, H.; Lou, D.; Hong, H.; Chen, H.; Liu, H.; Qiang, Y. Manufacturable Novel Nanogrease with Superb Physical Properties. Nanomanuf. Metrol. 2021, 1-9. [CrossRef] 